\title{
Formulaic language and conceptual socialization: The Route to becoming nativelike in L2
}

\author{
Deniz Ortaçtepe* \\ MA TEFL Program, Bilkent University, Ankara, Turkey \\ Received 16 February 2013; revised 22 July 2013; accepted 25 August 2013 \\ Available online 21 September 2013
}

\begin{abstract}
The present study addressed the question whether formulaic expressions indicate nativelike selection in the target language by examining seven Turkish students' use of formulaic expressions during their first year in the United States. Fourteen external raters who spoke English as their first language rated the Turkish (focal group) and American students' (control group) DCT responses in terms of nativelike language use. The results indicated that the American students not only received higher nativelikeness ratings but also produced more formulaic expressions than the Turkish students. This finding confirms that freely generated utterances based on grammatical units and lexis forecast non-membership to the speech community (Skehan, 1998) while the use of formulaic expressions $i$ an indicator of nativelike selection. The results also revealed that gaining competency over formulaic expressions for second language learners is not a linear process but open to creativity.
\end{abstract}

(c) 2013 Elsevier Ltd. All rights reserved.

Keywords: Conceptual socialization; Formulaic language; Nativelike language use

\section{Introduction}

Formulaic expressions, which are multi-word utterances that are stored and retrieved holistically from memory (Wray, 2000, 2002), have long received the attention of researchers due to their dominance over freely generated utterances (e.g., Coulmas, 1979, 1981; Erman and Warren, 2000; Ortaçtepe, 2012), and their role in not only reducing the processing-load (e.g., Jiang and Nekrasova, 2007; Kecskes, 2007; Pawley and Syder, 1983; Wray, 2002) but also enabling fluency in communication (e.g., Boers et al., 2006; Myles et al., 1999; Wood, 2006). The use of formulaic expressions indicates a speech community's preference of language use in certain situations (e.g., Kecskes, 2007; Tannen and Oztek, 1981), thus makes "language performance appear "native-like"” (Yorio, 1989, p. 56).

Researchers have long argued the role of formulaic expressions in the development of second language (L2) proficiency through longitudinal studies of exposure to the target language or through (quasi-) experimental studies that drew L2 learners' attention to these multi-word units (see Boers and Lindstromberg (2012) for a review of these studies). There is also a plethora of studies that explored the differences between nonnative and native speakers' use of these expressions (e.g., Bardovi-Harlig, 2009; Conklin and Schmitt, 2008; Siyanova and Schmidt, 2008; Siyanova-

\footnotetext{
* Tel.: +90554 6700475 .

E-mail address: denizortactepe@yahoo.com.
} 
Chanturia et al., 2011; Underwood et al., 2004). Contributing to the previous research mentioned above, the present study examines international students' acquisition of formulaic expressions throughout a single year they spent in the United States. By doing so, this study aims to investigate whether the use of formulaic expressions can be an indicator of nativelike language use. It is noteworthy to mention that this study acknowledges the native speaker fallacy and agrees to "the need to abandon the native speaker as the yardstick" (Jenkins, 2006, p. 175). Although the goal of language learning/teaching should not be geared towards becoming nativelike speakers of the target language (TL), this study argues that through residence in the TL country, language learners could develop familiarity with those formulaic expressions that characterize the TL speech community. In that sense, the present study adopts Davies' (1991) definition of native speaker who has "insider knowledge about 'their' language" (p. 1), and sets out to examine whether the use of formulaic expressions can reflect nativelikeness.

\section{Theoretical framework}

\subsection{Conceptual socialization}

Since nativelikeness, as understood in this study, can be developed only through exposure to the TL culture, this study employs Schieffelin and Ochs' (1986) language socialization as the theoretical framework. Language socialization can be defined as "a process requiring children's participation in social interactions so as to internalize and gain performance competence in these socio-cultural defined contexts" (Schieffelin and Ochs, 1986, p. 2). While Schieffelin and Ochs (1986) focused on first language (L1) acquisition, their framework has also inspired second language (L2) researchers who argue that language learning is a process of acquiring the linguistic forms as well as the cultural aspects of the TL (Watson-Gegeo, 2004). In that sense, L2 socialization refers to the process of "assimilation into the linguistic conventions and cultural practices of the L2 discourse communities" (Lam, 2004, p. 44).

Different terms have been proposed to address the specific features of L2 socialization such as pragmatic socialization (Blum-Kulka, 1997; Li, 2008), and socialization of taste (DuFon, 2006). Kecskes (2002), on the other hand, proposed the term conceptual socialization which refers to the process language learners, who reside in the TL culture, go through to "fit the functional needs of the new language and culture" (Kecskes, 2002, p. 157). The difference between conceptual socialization and L2 socialization is that, L2 learners, rather than simply acquiring the target language and its social norms, transform their conceptual system as a result of the bidirectional influence of the first and second languages (Kecskes, 2002). In other words, an L2 learner's L1 dominated conceptual base gradually develops to accommodate the new information coming from the TL culture (Ortaçtepe, 2012).

\subsection{The role of conceptual socialization in the acquisition of formulaic expressions}

Pre-fabricated speech, conversational routine, formulaic sequence, and routine formula are only some of the terms that have been used in the literature to refer to "multi-word collocations which are stored and retrieved holistically rather than being generated de novo with each use" (Kecskes, 2007, p. 193). The present study adopts the framework of conceptual socialization to examine whether these expressions indicate nativelikeness in the TL since a) extended stays in the TL culture provide rich input for formulaic expressions which dominate most communicative functions, and $b$ ) the group identifying nature of formulaic expressions helps interlocutors establish membership to the speech community.

First, not only research on L1 socialization (Schieffelin and Ochs, 1986) but also early studies on L2 socialization (e.g., Kanagy, 1999) have paid attention to the acquisition of interactional routines. This interest mostly results from the fact that "much of what is said in everyday interaction is by no means unique. Rather, a great deal of communicative activity consists of enacting routines, making use of prefabricated units in a well-known and generally accepted manner" (Coulmas, 1981, p. 1). Studies have suggested that natural exposure to the TL through extended stays in the TL culture will lead to nativelike idiomaticity through the use of interactional routines (Meunier, 2012; Siyanova and Schmidt, 2008; Wray, 2002). According to Howarth (1998), "native speaker linguistic competence has a large and significant phraseology component" (p. 29). Henceforth, when language learners enter the TL culture, not only will they be exposed to a variety of formulas, but also these expressions will be the very first things they will acquire through participation in different communicative contexts. In their review article, Burdelski and Cook (2012) discuss that formulaic language "is a powerful means and end of socialization" (p. 174). That is, while learning the norms and the values of the speech community, language learners also acquire the skills to engage in everyday 
interaction with the members of the speech community. As Roever's (2012) and Barron's (2003) studies indicate, while some formulaic expressions can be learned in the classroom, this process is much more rapid in the TL context since residence abroad provides not only rich input but also opportunities to interact with native speakers in a variety of contexts. Nevertheless, Dornyei, Durow and Zahran's (2004) study shows that although socio-cultural adaptation plays a major role, individual factors such as aptitude and motivation are also influential in the acquisition of formulaic expressions. In that sense, conceptual socialization provides a more comprehensive framework to explore the use of formulaic expressions since it requires a combination of "direct access to the target language, personal motivation for acculturation and a regular use of the target language" (Kecskes, 2002, p. 159).

Second, as Kecskes (2007) puts forward, "people belonging to a particular speech community have preferred ways of saying things (cf.Wray, 2002) and preferred ways of organizing thoughts" (p. 192). Thus, according Pawley and Syder (1983), adopting these formulaic expressions is a reflection of nativelike selection; that is, the ability to use the language not only appropriately but also in a way that is very sensitive to native speakers' preferences (Pawley and Syder, 1983; Bell, 2007). Howarth (1998) also suggests that "the ability to manipulate such clusters is a sign of true native speaker competence" (p. 38). Yorio's (1980) example of a North-American shop-attendant's saying "What can I do for you" versus "What do you want," the former being a routine formula while the latter is a grammatically and semantically accurate question, highlights how the latter could be in appropriate and even impolite at the pragmatic and sociolinguistic levels due to the preferences of the speech community. Therefore, formulaic expressions' groupidentifying nature (Yorio, 1980) is also an indicator of conceptual socialization since the use of these expressions in appropriate contexts requires shared experiences and common ground within a particular speech community (Kecskes, 2007).

Although there are several studies investigating the role of L2 socialization on the acquisition of pragmatic features (e.g., Matsumura, 2001), there are relatively fewer studies relating socialization to the acquisition of formulaic expressions. Kanagy's (1999) study, for instance, examined the use of formulaic expressions in a Japanese immersion classroom while Adolphs and Durow (2004), Barron (2003), Ortaçtepe (2012), and Roever (2012) looked into the effect of residence in the TL culture on the acquisition of formulaic expressions. However, whether the use of formulaic expressions is an indicator of nativelike language use is still an issue yet to be explored.

\section{The study}

\subsection{The research questions}

The present study, by examining Turkish international students' use of formulaic expressions in a pre and post-test design and by comparing their production with the American students, aims to address the following research questions:

a. How native-like are the responses of the English language users in the reference (American students) and the focal group (Turkish students)?

b. How formulaic are the responses of the Turkish students (focal group) across pre and post-tests?

It is crucial here to underline that the present study does not make a distinction between native and nonnative speakers of English but treats them both as users of English (Cook, 2002; Forsberg and Fant, 2010). In doing so, this study aims to demonstrate that nativelikeness is not a static standard but a relative, ever changing knowledge that is based on conventions and norms in a speech community. Therefore, people who have more exposure to that knowledge will be expected to show more nativelike language use (e.g., people born in that speech community), while people with a late-entry to the speech community (e.g., international or study abroad students) will gradually develop this insider knowledge (Kecskes, 2013) through conceptual socialization in the TL, which, as a result, would enable them to produce language that builds on a dual conceptual base that operates between L1 and L2 (Kecskes, 2002).

\subsection{The participants}

As indicated in the research questions, this study employs two groups of participants; a focal and a reference group. The focal group consists of seven Turkish international students (Baris, Melis, Hakan, Can, Sema, Serkan, and Erol - 
all pseudonyms) who were pursuing graduate degrees in the United States (U.S.) at the time of the study. The researcher, by using several social network webpages, announced a call for participation in a longitudinal study that required newcomer Turkish students. This friend-of-a-friend approach (Daming et al., 2008) enabled access to possible candidates who were later informed about the study. Once the informed consent was received from the participants, the study started off with the above mentioned seven participants who had just arrived in the States. All participants were advanced learners/users of English who met the TOEFL requirement for graduate enrollment. The seven Turkish students participated in this study were the ones who volunteered and met the requirements of the study.

Seven American students who were also pursuing graduate degrees in a large university in the U.S. formed the reference group who also volunteered for the study by responding to a similar announcement that was shared in several social network webpages as well as graduate student email lists. The reference group in this study served to reveal the expressions native speakers prefer since "formulas develop within communities, it is argued, as recurrent responses to recurrent communicative situations" (Durrant and Mathews-Aydinli, 2011). While this group completed the DCTs only once, the control group answered the DCTs in a pre and post-test design by completing them during their first month in the U.S. and 12-months after, respectively.

\subsection{The instrument}

Data for this study came from a 20-item discourse completion test (DCT), which can be defined as "written questionnaires including a number of brief situational descriptions followed by a short dialogue with an empty slot for the speech act under study" (Kasper and Dahl, 1991, p. 9).

An example of a DCT item is:

9th Situation: You just entered the library to drop off a book and there you ran into a friend.Friend: Hey, ... What's up?

You:

DCTs have long been criticized due to their nature of revealing what people would say in hypothetical contexts. However, their use was appropriate in this study since the participants' limited language production in the DCTs could lead to the comparisons between the focal and reference groups as well as the nativelikeness analysis conducted by the raters (soon to be discussed in more detail). This study would not have been possible with role-plays or narrative retellings since they create extensive discursive data that would not allow nativelikeness judgments. The DCTs used in this study were designed in such a way that it would yield to one particular formulaic response in the form of a single utterance. Designing extended response tasks in such a way would be quite difficult since the participants could use both formulaic and freely generated utterances. Also, doing the nativelikeness analysis for the raters even for single response DCTs took a lot of time and effort; it would be more difficult to find volunteers to rate the extended responses.

Establishing the validity of the DCT items involved two major steps: constructing the DCT items and conducting the pilot study. In the first step, 15 items were developed by reviewing the literature on formulaic expressions (Kecskes, 2000, 2002; Wray, 2002, 2008). During this step, expert opinion was taken from a renowned professor who published many studies on formulaic expressions. In the second step, the constructed 15-item DCT test was piloted with a sample of three Turkish students in a pre and post-test design.

The pilot study findings informed the present study in several ways. First of all, in the pilot study, the raters only rated the DCT responses. Yet, it was not enough just to get the ratings but the raters should have been asked to make a comment illustrating their rationale for their nativelikeness judgments. These comments could not only enhance the validity and the reliability of their ratings but also shed light on the language preferences of the raters. Also, in the pilot study, the raters only scored the Turkish speakers' responses. While some native speakers showed agreement on their judgments, often times there was considerable variance in their ratings. For this reason, adding American students' responses to the analysis could explain this variance and contribute to the reliability of native speakers' ratings. Last but not least, the pilot study findings showed that some items were too easy for the participants. Therefore, those easy items were replaced by new items so as to reflect a wider range of situations. Hence, after going through the same stages of the first version, the DCT test used in this study was developed with 20 items. 


\subsection{Formulaicity and nativelikeness analysis}

The present study aims to examine whether formulaic expressions can really indicate nativelike language use through two data analysis procedures: a formulaicity and a nativelikeness analysis.

First, the many functions and uses of formulaic expressions as well as the ambiguity in their definition (Wray, 2008) have led researchers to explore a variety of approaches to investigate these expressions (Biber, 2009). For instance, Wray and Namba (2003) proposed eleven criteria to identify formulaic expressions. Yet, the researchers cautioned that it still relies on the researcher's personal judgment to decide which criteria to follow based on the type of data available. In this study, Kecskes' (2007) formulaic continuum, as a more straightforward and recent framework, has been employed to determine the formulaicity of the participants' DCT responses. The formulaic continuum consists of six categories which include freely generated, semantic units, phrasal verbs, speech formula, situation-bound utterance and idioms. Although, each response has been analyzed in terms of these six categories, since the focus of this study was to examine whether a response is formulaic or not, in the last stage, the frequencies of all the categories except the freely generated ones have been summed and the results are presented as formulaic and freely generated utterances.

Second, in order to conduct the nativelikeness analysis, 20 American speakers of English, who were also graduate students, were contacted with an email explaining the aim of the study as well as the task that they would engage in if they were willing to participate. While all contacted American speakers agreed to rate the DCT responses, only 15 of them completed the analysis in a timely manner. All raters were provided with a copy of the responses with no names attached so that they would not know whether a particular response belonged to an American or Turkish student.

Since the nativelikeness analysis relied on the group-identifying nature of formulaic expressions, the raters were asked to read the DCT responses provided by the participants and rate them on a scale of $1-3,1$ being nonnative-like, and 3 nativelike. No definition of nativelikeness was provided; the raters were just asked to rate the responses in terms of whether they would normally say those DCT responses (Pawley, 2009). As Yorio (1980) suggests, native speakers during their conversations with L2 learners often think that "it just doesn't sound right" (p. 440), especially when L2 learners use formulaic expressions. Hence, the nativelikeness analysis not only enabled a comparison between the Turkish (focal group) and American participants (reference group), but also provided evidence for the reference group's preferred ways of saying things (Wray and Perkins, 2000).

Each participant's nativelikeness score was measured by adding up the ratings and then calculating the statistical means both for the focal and the reference group. At the end of the study, the Turkish students were contacted for member checking to explore why they produced certain expressions in particular DCT items.

\subsection{Interrater reliability}

Since the nativelikeness ratings, which depended on the raters' subjective evaluation of nativelike language use, constituted a major part of the data analysis, interrater reliability was an important concern to address in this study. Three major steps were followed to ensure inter-scorer reliability: First, the response rating sheet included clear and unambiguous instructions for scoring. Second, test-retest reliability was used to check whether the raters would score the responses the same way at two different times under equivalent conditions. To examine test-retest reliability, one of the raters received the same response set twice in three months apart. The Pearson Product Moment Correlation Coefficient for test-retest reliability was $.724(p<0.01)$, indicating a strong relationship between the ratings assigned at different times.

Third, the reliability analysis was conducted to examine the internal consistency within the other 14 raters who rated both pre and post-test responses. The procedure for the reliability analysis was twofold. First, each rater's mean was compared with others by calculating the scores they assigned to 20 DCT items for 14 participants (460 responses in total). The comparison of their means revealed that two raters, Rater D and Rater L, were outliers in pre and post tests, respectively. Deleting these two raters would improve Cronbach alpha the most. After excluding these two outliers from the analysis, Cronbach alpha for the pre and the post test was .933 and .937 , respectively, indicating a high internal consistency within the scores of 12 raters.

Finally, in order to measure the agreement among these 12 raters, a statistical procedure called Intra-class correlation was conducted. Single measures intraclass correlations for the reliability of a single rater (i.e., the reliability of individual raters) in the pre and the post test were .527 and .523 , respectively, both indicating a moderate agreement 
among the raters. On the other hand, the average measures (i.e., the reliability of the means of the ratings) for both tests revealed strong correlations, .930 for the pre-test and .929 for the post test.

\section{Results}

\subsection{The nativelike language use}

Turkish (pre and post-test) and American students' average ratings were calculated to understand the overall differences among these three groups.

As shown in Table 1, the Turkish students' nativelikeness rating increased from 2.33 to 2.52 in the post-test. On the other hand, the American speakers' responses were rated as 2.84, very much close to nativelike. The Kruskall Wallis H test revealed that the differences among the Turkish students' pre-test, post-test and American students were significant $(\mathrm{H}(2)=13.855, p=001)$. These results are important for the study for two main reasons. First, the positive change in Turkish students' nativelikeness ratings indicates a tendency towards more native-like use of English. Second, the higher ratings of the American students provide evidence for inter-rater reliability among the 12 raters. Even though no names were mentioned in the rating sheet, they all assigned higher ratings to the American students. Yet, it is interesting that the maximum score in the focal group's post-test - which belonged to Baris - is higher than the minimum score of the American students. This can be explained by the raters' subjective evaluation of nativelike language use, as also indicated by the absence of a perfect nativelike score for the reference group (Table 2).

As a second step, the average ratings that each Turkish student received across pre and post-tests were examined along with their American counterparts.

As displayed in Fig. 1, the Turkish students demonstrated an increase in their native-likeness. Especially Baris, Erol, Sema and Serkan received relatively higher ratings in their post-test, while the increase in Hakan's and Melis' ratings was not as large as the others. Only Can's ratings displayed a decrease from 2.68 to 2.64 for the reasons that will be mentioned in the next part. While Melis received the lowest ratings in pre and post-tests, 1.92 and 2.07, respectively, Can earned the highest ratings in the pre-test, 2.68, and Baris received the highest rating in the post-test, 2.78. These findings show that although Turkish students demonstrated an increase in their nativelikeness, their ratings were still much lower than the mean of the American participants as indicated in the straight line in Fig. 1.

\subsection{Turkish students' use of formulaic language}

The Turkish students' acquisition of formulaic expressions, as indicated by their DCT responses, displayed a nonlinear pattern in the sense that while some expressions were acquired and used appropriately, some have been omitted for more creative, freely generated responses. This section, in that sense, will provide examples from the Turkish students' a) accurate responses, b) creative responses, and c) inaccurate responses that remained the same across pre and post-tests.

\subsubsection{Accurate responses}

As shown in Fig. 1, Baris was one of the participants who increased his nativelikeness in the post-test. This increase mostly resulted from the change in his responses to DCT \# 13 and DCT \# 19.

DCT \# 13 is the item that Baris received the lowest nativelikeness rating in the pre-test. The rater agreement for this item was $100 \%$, all agreeing that Baris' pre-test response was 1.00, nonnative like. The raters thought "I just want to meet you" as a response to "I didn't catch your name" was "in appropriate, weird and unwarranted." Contrary to his

Table 1

The descriptives of Turkish and American students' nativelikeness ratings.

\begin{tabular}{|c|c|c|c|c|c|}
\hline & $N$ & Minimum & Maximum & $M$ & SD \\
\hline Turkish students: pre-test & 7 & 1.92 & 2.68 & 2.33 & .243 \\
\hline Turkish students: post-test & 7 & 2.07 & 2.78 & 2.52 & .225 \\
\hline American students & 7 & 2.73 & 2.93 & 2.84 & .078 \\
\hline
\end{tabular}


Table 2

Baris' pre and post-test responses to DCT\# 13.

\begin{tabular}{lll}
\hline DCT\# 13 & 13th situation: You are invited to a party where you meet several new people. \\
& You: Hi, Dennis. Nice to meet you. \\
& The new person: I'm sorry, I didn't catch your name. \\
& You:....................................................... & Post-test \\
\cline { 2 - 3 } & Pre-test & That's ok, my name is Baris. \\
\hline Baris' response & I just want to meet you & Sounds like something I would say, Normalish, OK \\
Rativelikeness rating & 1.00 & \\
Raters' comments & Unwarranted, I don't think the situation was understood, & \\
& Totally in appropriate, Sounds really weird, stalkerish-like & \\
\hline
\end{tabular}

pre-test response, Baris, in the post-test, demonstrated an understanding of the formulaic expression "I didn't catch your name" by repeating his name as a response. His post-test response was rated as 2.91 , very close to 3 , nativelike.

DCT \# 19 also provides an example in which Baris was not familiar with the expression in the pre-test but gained competency over in the post-test.

As displayed in Table 3, in the pre-test, Baris was not familiar with the idiomatic expression "come again," hence interpreted its literal meaning. As a result, he received the second-lowest rating of his pre-test responses: 1.18. His post-test response illustrates a positive change in terms of how he gained competency in this formulaic expression and how this competency resulted in an increase in his nativelikeness. All the raters, with a $100 \%$ agreement, scored his post-test response as 3, nativelike.

As far as the items in which Hakan demonstrated an increase, DCT \# 12 seems to be the most interesting one since he received the lowest rating on the pre-test for this item.

As represented in Table 4, there is a striking difference between Hakan's pre and post-test responses since in the pre-test, he responded to the literal meaning of the expression and had, therefore, received a rating of 1.09, nonnative like. In the post-test, Hakan recognized the figurative meaning of "get out of here." His post-test response was pragmatically correct since he insisted on his previous presupposition. His response should also be compared with the American students who participated in the study as a reference group.

As illustrated in Table 5, all the American students started their response with either "No, really" or "No, serious," implying that they were really serious in their presupposition. Their responses indicate the preferred ways of responding to the formulaic expression "get out of here" in this specific context. In this respect, while Hakan's pre-test response failed to recognize the pragmatic, figurative meaning of the formulaic expression "get out of here," his posttest response was a step towards the preferred ways of saying things in the American culture. Yet, the problems in tense and the way he responded were considered to be problematic by some reviewers, cutting back his response to 2.45 (Table 6).

\subsubsection{Preference for creativity}

In some of the items, the Turkish students, even though they provided an appropriate formulaic response in the pretest, omitted those expressions and provided a creative, freely generated response in the post-test, which resulted in a

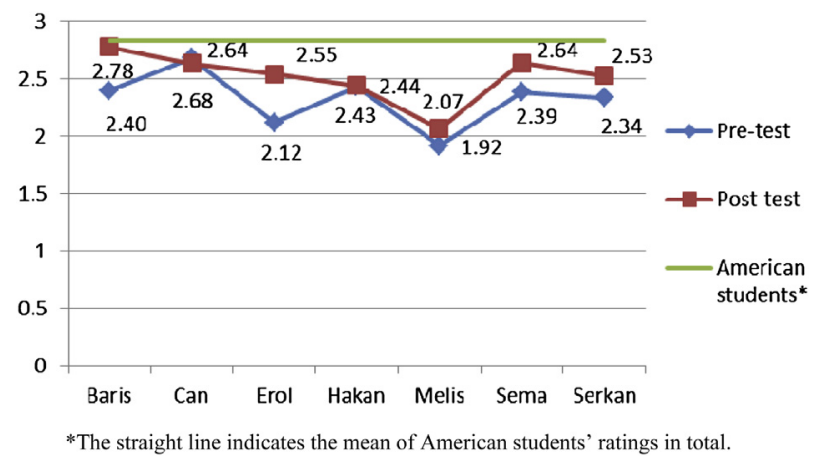

Fig. 1. The nativelikeness ratings of Turkish and American students. *The straight line indicates the mean of American students' ratings in total. 
Table 3

Baris' pre and post-test responses to DCT\# 19.

\begin{tabular}{|c|c|c|}
\hline \multirow[t]{2}{*}{ DCT\# 19} & \multicolumn{2}{|l|}{ 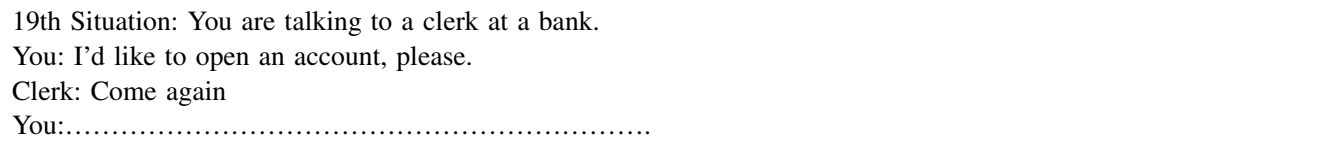 } \\
\hline & Pre-test & Post-test \\
\hline $\begin{array}{l}\text { Baris' response } \\
\text { Nativelikeness rating }\end{array}$ & $\begin{array}{l}\text { What do you mean by “come again” Aren't you guys working now? } \\
1.18\end{array}$ & $\begin{array}{l}\text { I'd like to open an account, please. } \\
3.00\end{array}$ \\
\hline Raters' comments & $\begin{array}{l}\text { Person didn't understand "come again" meant to repeat ones self. } \\
\text { Usually come again means, repeat what you said in our culture, } \\
\text { but this person didn't know that }\end{array}$ & Sounds like something I would say, OK \\
\hline
\end{tabular}

decrease in their nativelikeness ratings. Serkan's decrease in DCT \# 18 is a good example for this pattern since his rating in the pre-test dropped from 3.00 to 1.91 in the post-test.

In the pre-test, Serkan managed to provide a preferred response which gave him a full score of nativelike with a $100 \%$ rater agreement. Obviously, Serkan knew how to respond to the figurative meaning of "I'll talk to you later" in the pre-test. That's why, it was really difficult to interpret why he responded as "you better be. Of course you will" in the post-test. During the member checking sessions, Serkan mentioned that one of his professors at the university was responding to "I'll talk to you later" in the same way as a joke and that was how he picked up that response. Thus, Serkan knew that "Bye" was the typical response in that situation but he wanted to say something different in that context. This tryout resulted in a decrease in his nativelikeness since that was not the response that the raters were accustomed to. The responses of American students also provide evidence for what is a common response and why Serkan's post-test response was perceived as in appropriate in this context.

As shown in Table 7, most of the American students responded with either "Bye" or "Sounds good." Even though the last response is the only different one (excluding "Later" which is a substitute for "bye"), it still received 3, nativelike from all the raters (100\% rater agreement). In that sense, Serkan could have responded in a different way and still received a higher rating if he had not generalized his professor's joke to this specific context (Table 8) (Table 9) (Table 10).

Can's response to DCT \# 20 also provides a good example for the Turkish students' preference for creativity over formulaic expressions.

As evidenced by Can's pre-test response, he had access to the figurative meaning of "hang on for a second." His pretest response was rated nativelike by all the raters with $100 \%$ rater agreement. During the member checking session, Can said that:

I call my friend and he says "hang on" as soon as he answers, so I am surprised, that's why I say "excuse me." (All these nonsense responses are only because I didn't want to give the same responses as in the pre-test.)

Serkan and Can were the only participants who tried to provide different responses, which resulted in a decrease in their nativelikeness. These examples suggest that once certain expressions are acquired, language learners look for alternative ways to respond to the situation by using different language resources which might lead them to produce a

Table 4

Hakan's pre and post-test responses to DCT\# 12.

DCT\# 12 12th Situation: You and a friend of yours are talking about a job promotion that You think your friend deserved.

You: Jason, I think you really deserved that promotion.

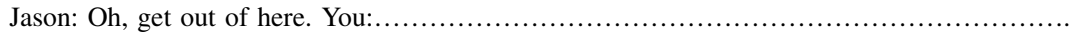

\begin{tabular}{lll} 
& Pre-test & Post-test \\
\cline { 2 - 3 } Hakan's response & I didn't mean to bother you. & Yes, I think you really deserve that! \\
Nativelikeness rating & 1.09 & 2.45 \\
Raters' comments & Person did not understand; & Form: "deserve" vs "deserved"; verb tense; I think I would use the \\
& Not an appropriate response. & past tense; I would've said, "seriously, I really think you deserved it." \\
\hline
\end{tabular}


Table 5

American students' responses to DCT\# 12.

American students' responses to DCT\# 12

- No, really. You are a great worker and have done a lot for the company. I can't imagine why they would offer the position to someone else.

- No, really. I think you'd be great at it

- No, really, I hope it goes well for you.

- No, really. You deserved it.

- No, really. Your one of the most talented people in your department.

- No really. You did a great job.

- No seriously you have been working really hard.

Table 6

Serkan's pre and post-test responses to DCT\# 18

\begin{tabular}{|c|c|c|}
\hline \multirow[t]{2}{*}{ DCT\# 18} & \multicolumn{2}{|c|}{$\begin{array}{l}\text { 18th situation: You and your friend are talking in a coffee shop. } \\
\text { You: I have to be going now. See you soon. } \\
\text { Your friend: OK, I'll talk to you later. } \\
\text { You: } \ldots \ldots \ldots \ldots \ldots \ldots \ldots \ldots \ldots \ldots \ldots \ldots \ldots \ldots \ldots \ldots \ldots \ldots \ldots \ldots \ldots \ldots \ldots \ldots \ldots \ldots \ldots \ldots \ldots\end{array}$} \\
\hline & Pre-test & Post-test \\
\hline Serkan's response & Bye & You better be. Of course you will. \\
\hline Nativelikeness rating & 3.00 & 1.91 \\
\hline Raters' comments & Normal, Typical response & $\begin{array}{l}\text { Apparently doesn't understand the situation, This doesn't make sense to me. } \\
\text { Better be doesn't make sense. }\end{array}$ \\
\hline
\end{tabular}

non-formulaic response. Yet, as mentioned in the literature review, native speakers of a language have preferred ways of saying things (Wray and Perkins, 2000). While a simple "OK" or "thank you" is enough to be perceived as nativelike, being creative and adding additional information seem to have made the raters cut back in their nativelikeness ratings, as evidenced in Serkan's and Can's cases.

\subsubsection{Inaccurate responses}

Even though most of the participants demonstrated positive changes in their nativelikeness ratings, there were still some items that remained the same across pre and post-tests, indicating that these expressions were still not available to the participants. Erol's response to DCT \# 12 provides a good example for these inaccurate responses.

All the raters with a 100\% agreement rated Erol's opting for no response as 1, nonnative like. The raters' comments, however, were torn between those who thought "Erol did understand the figurative meaning but thought no response was needed" vs. "those who thought Erol did not get the meaning." During the member-checking sessions, Erol revealed that he was not familiar with the figurative meaning of the expression but interpreted its literal meaning as "get out of here." Thus, he thought he would rather not respond to the person. His interpretation of the expressions' literal meaning did not change in the post-test, leaving him with a non-nativelike score.

In a similar way, Melis struggled with DCT \# 19 for which she received similar ratings in pre and post-tests, both being lower than 1.5 (non-nativelike).

Table 7

American students' responses to DCT\# 18.

American students' responses to DCT\# 18

Bye

Sounds good.

Later

Bye

Sounds good!

Sounds good

Yeah definitely. Give me a call sometime and we'll go out for wing night or grab a beer or smt. 
Table 8

Can's pre and post-test responses to DCT\# 20.

\begin{tabular}{lll}
\hline DCT\# 20 & 20th situation: You call a friend of yours. He picks up the phone and says: \\
& Your Friend: Hi, Hang on for a second. \\
& You: $\ldots \ldots \ldots \ldots \ldots \ldots \ldots \ldots \ldots \ldots \ldots \ldots \ldots \ldots \ldots \ldots \ldots \ldots \ldots \ldots \ldots \ldots \ldots \ldots$ \\
\cline { 2 - 3 } & Pre-test & Post-test \\
\hline Can's response & OK & Excuse me? \\
Nativelikeness rating & 3.00 & 2.27 \\
Raters' comments & Sounds like something I would say; & This person doesn't understand or just did not hear; \\
& Typical response; Normal & You just don't say that; Misunderstanding? \\
\hline
\end{tabular}

In both pre and post-tests, Melis provided similar responses indicating that she does not have access to the figurative meaning of the formulaic expression "come again." The raters also agreed that Melis did not understand that "come again" meant "repeat oneself", and therefore they rated Melis' pre and post responses below 1.5, or nonnative like. As illustrated in these examples, the Turkish students have started to pick up some formulaic expressions and demonstrated competency in their use, yet they are still going through the process of acquiring not only the expressions per se but the appropriate use of them.

\section{Discussion}

\subsection{Formulaic expressions as indicators of nativelikeness}

In his paper reviewing the last 30 years of research on formulaic language, Pawley (2007) stated that "Speaking a language idiomatically is a matter of conforming to established ways of saying things" (p. 22). In that sense, as the first empirical study examining the role of formulaic expressions in nativelike language use, this research has shown that the use of formulaic expressions is an indicator of nativelike selection. The increase in the Turkish students' nativelikeness ratings supports Wray's (2004) premise that "in a fully predictable situation, it should be easy for a language learner to pass herself off as nativelike (apart from pronunciation), because all she has to do is memorise a set of nativelike sentences" (p. 251).

The fact that the American students in this study not only received higher nativelikeness ratings but also produced more formulaic expressions as opposed to the Turkish students confirms that freely generated utterances based on grammatical units and lexis forecast non-membership to the speech community (Skehan, 1998) since "native speakers do not say it in that way" (Shin and Nation, 2008, p. 340). Hence, as a result of their one-year conceptual socialization in the U.S., the Turkish students in this study not only increased their use of formulaic expressions but also were perceived as more nativelike by responding in a way that is preferred by the native speaker raters. For instance, Baris' nativelikeness rating in the post-test increased from 1.18 to 3 , a nativelike score with a $100 \%$ rater agreement, since he provided a response that showed understanding of the figurative meaning of the expression "come again." These findings are in line with the research examining the functions of formulaic expressions in L2 learners' development of speech fluency. While previous research revealed that formulaic expressions promote oral proficiency (Boers et al.,

Table 9

Erol's pre and post-test responses to DCT\# 12.

\begin{tabular}{|c|c|c|}
\hline \multirow[t]{2}{*}{ DCT\# 12} & 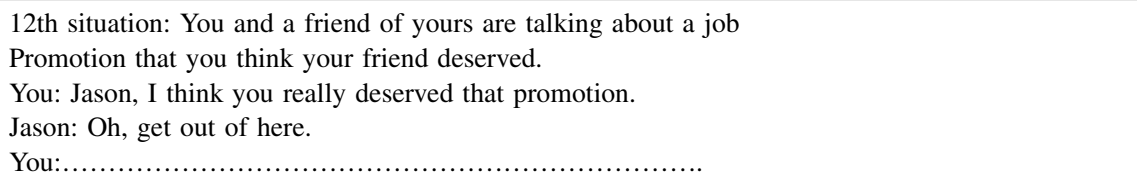 & \\
\hline & Pre-test & Post-test \\
\hline Erol's response & (Normally I do not answer in case of such response) & (Nothing to say) \\
\hline Nativelikeness rating & 1.00 & 1.00 \\
\hline Raters' comments & $\begin{array}{l}\text { Clearly the person didn't understand; I think not responding is a response to the question; } \\
\text { It would be weird if you let that be the last statement, like you meant what the friend said instead }\end{array}$ & \\
\hline
\end{tabular}


Table 10

Melis' pre and post-test responses to DCT\# 19.

\begin{tabular}{|c|c|c|}
\hline \multirow[t]{2}{*}{ DCT\# 19} & \multicolumn{2}{|c|}{ 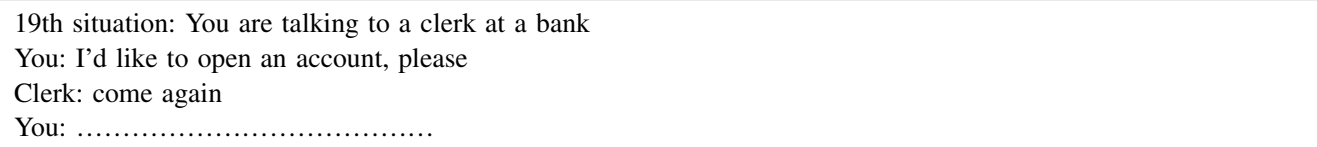 } \\
\hline & Pre-test & Post-test \\
\hline Erol's response & $\begin{array}{l}\text { Sorry, This is urgent for me. } \\
\text { Is it possible to do it today? }\end{array}$ & $\begin{array}{l}\text { Sorry but why I cant open it right now. I prepared all the documents } \\
\text { needed and I need the account as soon as possible for my salary } \\
\text { payments. Please can (I) make it right now if possible. }\end{array}$ \\
\hline Nativelikeness rating & 1.36 & 1.27 \\
\hline Raters' comments & $\begin{array}{l}\text { Person didn't understand "come again" } \\
\text { meant to repeat oneself. }\end{array}$ & $\begin{array}{l}\text { I should be able to give a } 0 \text {. So wrong; Obviously the speaker is } \\
\text { not familiar with the expression 'Come again.' }\end{array}$ \\
\hline
\end{tabular}

2006) as well as speech fluency by allowing language learners to extend the length of runs between pauses (Wood, 2006), the present study showed that this relationship exists both at the speech and interactional discourse level since the use of formulaic expressions enables language learners to fit into the speech context as persons who have insider knowledge. In that sense, this study confirms that language learners need more than simply acquiring grammatical features and lexis to express themselves but to "become sensitive to the native speakers' preferences for certain sequences of words over others that might appear just as possible" (Wray, 2000, p. 463). This process, then, calls for conceptual socialization in the TL culture so that language learners will acquire the knowledge of sociocultural background, the culture-specific communicative functions and patterns as well the pragmatic properties of these formulaic expressions through observations of language use in the TL (Kecskes, 2002).

\subsection{Use of formulaic expressions by language learners}

The findings of this study also indicated that gaining competency over the speech community's preferences is not a linear process in which learners acquire the use of formulaic expressions and competently use them in particular contexts. Instead, this process is subjected to creativity through the use of freely generated utterances. Serkan and Baris' alternative responses in the post-test indicate that these learners preferred to generate new utterances rather than resorting to formulaic expressions. In other words, once learners gain competency over certain expressions they might prefer to create or produce freely generated utterances (e.g., Ortaçtepe, 2012). Wray (2002) suggests that advanced learners' tendency toward free formulation results in "perfectly grammatical utterances that are simply not used by native speakers" (p. 140, emphasis added). It is noteworthy to mention that the creative activity discussed here is different from not being familiar with a certain formulaic expression but producing a freely generated one instead. It is the type of creativity, which is commonly called creativity idiomaticity (e.g., He, 1989; Prodromou, 2010; Vo and Carter, 2010) that competent language users employ not to sound cliché, to bring humor to a conversation or to establish solidarity within a group. Yet, it is the interplay of context, the formulaic expression and its pragmatic function that determine the appropriate use of an expression (Bardovi-Harlig, 2009). Thus, this type of contextsensitive creative activity, as in Serkan's response "you better be, of course you will" to the expression "I'll talk to you later," could be challenging for language learners who need more than receptive and/or productive competence in these expressions but to develop the understanding that formulaic expressions are strictly tied to specific contexts and most of the times are the expected, preferred response in a speech community. As Bardovi-Harlig (2012) mentioned in a recent review article, "Formulas often succinctly capture the illocutionary force of a contribution by virtue of the fact that the speech community in which they are used has tacitly agreed on their form, meaning, and use" (p. 207). In that sense, the nativelikeness ratings in this study confirm that native speakers do have preferred ways of saying things (Wray and Perkins, 2000) and when L2 learners produce freely generated utterances in a context where a formulaic expression is expected, their deliberate creativity might result in them being perceived as non-nativelike.

\subsection{Possible factors determining the use of formulaic expressions}

As the findings indicate, despite the increase in Turkish students' use of formulaic expressions across pre and posttests, the extent of the formulaic language they used as well as their nativelikeness ratings were far behind the 
American students in the reference group. This finding can be explained by three factors that have been extensively discussed in the literature: formulaic expressions' frequency of occurrence, language learners' familiarity with those contexts that require formulaicity, and noticing.

One of the interesting findings this study revealed was that some formulaic expressions remained problematic for the Turkish students across pre and post-tests. This finding might derive from the difference between low and high frequency expressions (e.g., Durrant and Schmitt, 2009; Ellis et al., 2008). For instance, 'get out of here' is an expression that might be easily picked up through exposure to informal settings (e.g., friendly conversation) while the use of 'come again' might take longer to acquire since this formulaic expression occurs in more restricted speech contexts (e.g., service encounters). As Forsberg and Fant (2010) highlight, "all language learners, native or non-native, master formulaic sequences associated with "common' situations better than those occurring in unfamiliar situations" (p. 49). In that sense, another factor that is related to the frequency of occurrence is language learners' familiarity with a variety of speech contexts so that they can enhance their chances of receiving input to acquire both low and high frequency expressions. Especially if language learners come from a culture where such practices are unlikely to occur, as in the expression 'to pull some strings' (He, 1989), or in appropriate and rude as in the expression, 'get out of here' (Kecskes, 2002), adopting these expressions could only take place with the transformation of the conceptual system of the language learner through socialization in the TL culture. Erol's refusal to respond to 'get out of here,' is a good example because by relying on his Turkish conceptual system, he interpreted the semantic/literal meaning of the expression rather its pragmatic function. Thus, conceptual socialization is of paramount importance in the sense that through the emergence of the common underlying conceptual base, language learners will gain access to "not only the pragmatic function of the utterance but also the formula-specific pragmatic property of the expression" (Kecskes, 2002, p. 163).

While formulaic expressions' frequency of occurrence and learners' participation in a variety of contexts are two important factors that could explain the degree of change in the Turkish students' responses, another influential factor especially in naturalistic settings is what Schmidt (1990) describes as noticing, a precondition for a particular language item to be integrated into the interlanguage of an L2 learner. In Boers et al. (2006) study that examined the effect of a noticing-based instructional method on L2 learners' use of formulaic expressions, phrase-noticing was found to be an effective method to help learners boost their use of formulaic expressions. In another study, Bardovi-Harlig and Vellenga (2012) found that guided metapragmatic noticing activities enabled language learners to use especially those conventional expressions that "are relatively transparent and consistent with the learners' current interlanguage grammar" (p. 86). In that sense, the findings of this study also contribute to the discussion that mere exposure to the second language might not be sufficient for L2 pragmatic development (e.g., Boers et al., 2006; Tateyama, 2001).

\section{Conclusion}

This study addressed the question whether formulaic expressions indicate nativelike selection in the target language by examining seven Turkish students' use of formulaic expressions during their first year in the United States. Hence, one limitation of this study was its reliance on the native speaker raters' subjective evaluation of nativelike language use. Especially for a study that aims to explore whether the use of formulaic expressions can indicate nativelike selection, there seems to be no alternative but to elicit data both from Turkish and American speakers of English and ask external native speaker raters to make judgments in terms of whether the DCT responses sound nativelike or not. Also, although DCTs were the most practical instrument to serve the purpose of this study, researchers should be cautious in using DCTs along with naturalistic data such as recorded conversations so that the claims made based on DCTs could be supported with occurrences in real-life like contexts. Several data collection instruments might also prevent the practice effect that was encountered in this study, as indicated in Can's attempt not to repeat himself in the post-test.

The other limitation of the study is that there was no qualitative data to shed light on the language socialization experiences of the participants. The fact that Baris provided an appropriate response to 'come again' in his post DCT, while Melis could not, calls attention to learners' socialization experiences that might differ radically from each other (e.g., Adolphs and Durow, 2004; Dornyei et al., 2004; Kinginger and Blattner, 2007; Ortaçtepe, 2012). The two longitudinal studies on the acquisition of formulaic expressions revealed that social integration through different social networks within the host culture enables international students to adapt native speakers' preferred ways of saying things (Adolphs and Durow, 2004; Ortaçtepe, 2012). In that sense, further research can examine the role of "the 
variables that characterize the stay" (Bardovi-Harlig and Bastos, 2011, p. 376) in the acquisition of formulaic expressions through narratives or in-depth interviews.

\section{References}

Adolphs, S., Durow, V., 2004. Social-cultural integration and the development of formulaic sequences. In: Schmitt, Norbert (Ed.), Formulaic Sequences: Acquisition, Processing and Use. John Benjamins, Philadelphia, pp. 107-127.

Bardovi-Harlig, K., 2012. Formulas, routines, and conversational expressions in pragmatics research. Annu. Rev. Appl. Linguistics 32, $206-227$.

Bardovi-Harlig, K., 2009. Conventional expressions as a pragmalinguistic resource: recognition and production of conventional expressions in L2 pragmatics. Lang. Learn. 59 (4), 755-795.

Bardovi-Harlig, K., Bastos, M.T., 2011. Proficiency, length of stay, and intensity of interaction, and the acquisition of conventional expressions in L2 pragmatics. Intercult. Pragmatics 8 (3), 347-384.

Bardovi-Harlig, K., Vellenga, H.E., 2012. The effect of instruction on conventional expressions in L2 pragmatics. System 40 (1), $77-89$.

Barron, A., 2003. Acquisition in Interlanguage Pragmatics: Learning How to Do Things with Words in a Study Abroad Context. John Benjamins, Amsterdam.

Bell, N.D., 2007. How native and non-native English speakers adapt to humor in intercultural interaction. Humor 20 (1), $27-48$.

Biber, D., 2009. A corpus driven approach to formulaic language in English: multi-word patterns in speech and writing. Int. J. Corpus Linguistics 14 (3), 275-311.

Blum-Kulka, S., 1997. Dinner Talk: Cultural Patterns of Sociability and Socialization in Family Discourse. Lawrence Erlbaum, Mahwah, NJ.

Boers, F., Lindstromberg, S., 2012. Experimental and intervention studies on formulaic sequences in a second language. Annu. Rev. Appl. Linguistics 32, 83-110.

Boers, F., Eyckmans, J., Kappel, J., Stengers, H., Demecheleer, M., 2006. Formulaic sequences and perceived oral proficiency: putting a lexical approach to the test. Lang. Teach. Res. 10 (3), 245-261.

Burdelski, M., Cook, H.M., 2012. Formulaic language in language socialization. Annu. Rev. Appl. Linguistics 32, $173-188$.

Conklin, K., Schmitt, N., 2008. Formulaic sequences: are they processed more quickly than nonformulaic language by native and nonnative speakers? Appl. Linguistics 29 (1), 72-89.

Cook, V. (Ed.), 2002. Portraits of the L2 User. Multilingual Matters, Great Britain.

Coulmas, F., 1981. Introduction: conversational routine. In: Coulmas, Florian (Ed.), Conversational Routine. Mouton de Gruyter, Netherlands, pp. $1-19$.

Coulmas, F., 1979. On the sociolinguistic relevance of routine formulas. J. Pragmatics 3, 239-266.

Daming, X., Xiaomei, W., Wei, L., 2008. Social network theory. In: Wei, L., Moyer, M.G. (Eds.), The Blackwell Guide to Research Methods in Bilingualism and Multilingualism. Blackwell Publishing, Singapore, pp. 263-274.

Davies, A., 1991. The Native Speaker in Applied Linguistics. Edinburgh University Press, Edinburgh.

Dornyei, Z., Durow, V., Zahran, K., 2004. Individual differences and their effects on formulaic sequence acquisition. In: Schmitt, Norbert (Ed.), Formulaic Sequences: Acquisition, Processing and Use. John Benjamins, Philadelphia, pp. 87-107.

DuFon, M.A., 2006. The socialization of taste during study abroad in Indonesia. In: DuFon, Margaret A., Churchill, Eton (Eds.), Language Learners in Study Abroad Contexts. Multilingual Matters, Great Britain, pp. 91-120.

Durrant, P., Mathews-Aydinli, J., 2011. A function-first approach to identifying formulaic language in academic writing. English Specif. Purposes $30,58-72$.

Durrant, P., Schmitt, N., 2009. To what extent do native and non-native writers make use of collocations. IRAL 47, $157-177$.

Ellis, C.N., Simpson-Vlach, R., Maynard, C., 2008. Formulaic language in native and second language speakers: psycholinguistics, corpus linguistics, and TESOL. TESOL Q. 42 (3), 375-396.

Erman, B., Warren, B., 2000. The idiom principle and the open-choice principle. Text 20, 29-62.

Forsberg, F., Fant, L., 2010. Idiomatically speaking: effects of task variation on formulaic language in highly proficient users of L2 French and Spanish. In: Wood, David (Ed.), Perspectives on Formulaic Language: Acquisition and Communication. Continuum, Great Britain, pp. 47-71.

He, Z., 1989. Creative idiomaticity. In: Hall, Kira, Meacham, Micheal, Shapiro, Richard (Eds.), Proceedings of the 15th Annual Meeting of the Berkeley Linguistics Society, February 8-20, 1989. Berkeley Linguistics Society, Berkeley, CA.

Howarth, P., 1998. Phraseology and second language proficiency. Appl. Linguistics 19 (1), 24-44.

Jenkins, J., 2006. Current perspectives on teaching World Englishes and English as a Lingua Franca. TESOL Q. 40 (1), $157-181$.

Jiang, N., Nekrasova, T.M., 2007. The processing of formulaic sequences by second language speakers. Mod. Lang. J. 91 (3), $433-445$.

Kanagy, R., 1999. Interactional routines as a mechanism for L2 acquisition and socialization in an immersion context. J. Pragmatics 31, 1467-1492.

Kasper, G., Dahl, M., 1991. Research methods in interlanguage pragmatics. Stud. Second Lang. Acquisition 13 (2), $215-248$.

Kecskes, I., 2013. Intercultural Pragmatics. Oxford University Press, Oxford. Forthcoming.

Kecskes, I., 2007. Formulaic language in English Lingua Franca. In: Kecskes, Istvan, Horn, Laurence R. (Eds.), Explorations in Pragmatics. Mouton de Gruyter, Germany, pp. 191-219.

Kecskes, I., 2002. Situation-bound Utterances in L1 and L2. Mouton de Gruyter, Berlin/New York.

Kecskes, I., 2000. Conceptual fluency and the use of situation-bound utterances in L2. Links Lett. 7, 145-161.

Kinginger, C., Blattner, G., 2007. Assessing the development of sociolinguistic awareness in study abroad: colloquial French. In: Ortega, Lourdes, Byrnes, Heidi (Eds.), The Longitudinal Study of Advanced L2 Capabilities. Erlbaum, Mahwah, NJ, pp. 223-246.

Lam, W.S.E., 2004. Second language socialization in a bilingual chat room: global and local considerations. Lang. Learn. Technol. 8, 44-65. 
Li, D., 2008. Pragmatic socialization. In: Duff, Patricia, Hornberger, Nancy H. (Eds.), Language Socialization. Springer, NY, pp. 87-100.

Matsumura, S., 2001. Learning the rules for offering advice: a quantitative approach to second language socialization. Lang. Learn. 51, 635-679. Meunier, F., 2012. Formulaic language and language teaching. Annu. Rev. Appl. Linguistics 32, 111-129.

Myles, F., Hooper, J., Mitchell, R., 1999. Rote or rule? Exploring the role of formulaic language in classroom foreign language learning. Lang. Learn. 48 (3), 323-363.

Ortaçtepe, D., 2012. The Development of Conceptual Socialization in International Students: a Language Socialization Perspective on Conceptual Fluency and Social Identity. Cambridge Scholars Publishing, UK.

Pawley, A., 2009. Grammarians' languages versus humanists' languages and the place of speech act formulas in models of linguistic competence. In: Corrigan, Roberta, Moravcsik, Edith A., Ouali, Hamid, Wheatley, Kathleen M. (Eds.), Formulaic Language, Distribution and Historical Change, vol. I. John Benjamins, Amsterdam, pp. 3-27.

Pawley, A., 2007. Developments in the study of formulaic language since 1970: a personal view. In: Skandera, Paul (Ed.), Phraseology and Culture in English. Mouton de Gruyter, Germany, pp. 1-48.

Pawley, A., Syder, F.H., 1983. Two puzzles for linguistic theory: nativelike selection and nativelike fluency. In: Richards, Jack C., Schmidt, Richard W. (Eds.), Language and Communication. Longman, London, pp. 191-226.

Prodromou, L., 2010. Bumping into creative idiomaticity. In: Cook, Guy, North, Sarah (Eds.), Applied Linguistics in Action: A Reader. Routledge, UK, pp. 231-245.

Roever, C., 2012. What learners get for free: learning of routine formulae in ESL and EFL environments. ELT J. 66 (1), $10-22$.

Schieffelin, B.B., Ochs, E., 1986. Language Socialization across Cultures. Cambridge University Press, USA.

Schmidt, R., 1990. The role of consciousness in second language learning. Appl. Linguistics 11, 129-158.

Skehan, P., 1998. A Cognitive Approach to Language Learning. Oxford University Press, Oxford.

Shin, D., Nation, P., 2008. Beyond single words: the most frequent collocations in spoken English. ELT J. 62 (4), $339-348$.

Siyanova-Chanturia, A., Conklin, K., Schmitt, N., 2011. Adding more fuel to the fire: an eye-tracking study of idiom processing by native and non-native speakers. Second Lang. Res. 27, 1-22.

Siyanova, A., Schmidt, R.W., 2008. L2 learner production and processing of collocation: a multi-study perspective. Can. Mod. Lang. Rev. 64 (3), 429-458.

Tannen, D., Oztek, P.C., 1981. Health to our mouths: formulaic expressions in Turkish and Greek. In: Coulmas, Florian (Ed.), Conversational Routine. Mouton Publishers, The Netherlands, pp. 37-55.

Tateyama, Y., 2001. Explicit and implicit teaching of pragmatic routines. In: Kasper, Gabriele, Rose, Kenneth R. (Eds.), Pragmatic Development in a Second Language. Blackwell Publishing, USA, pp. 220-222.

Underwood, G., Schmitt, N., Galpin, A., 2004. The eyes have it: an eye-movement study into the processing of formulaic sequences. In: Schmitt, N. (Ed.), Formulaic Sequences. John Benjamins, the Netherlands, pp. 153-172.

Vo, A.T., Carter, R., 2010. What can a corpus tell us about creativity? In: O'Keeffee, Anne, McCarthy, Micheal (Eds.), The Routledge Handbook of Corpus Linguistics. Routledge, UK, pp. 302-315.

Watson-Gegeo, K.A., 2004. Mind, language, and epistemology: toward a language socialization paradigm for SLA. Mod. Lang. J. 88 (3), $331-350$.

Wood, D., 2006. Uses and functions of formulaic sequences in second language speech: an exploration of the foundations of fluency. Can. Mod. Lang. Rev. 63 (1), 13-33.

Wray, A., 2008. Formulaic Language: Pushing the Boundaries. Oxford University Press, Oxford.

Wray, A., 2004. Here's one I prepared earlier: formulaic language learning on television. In: Norbert, S. (Ed.), Formulaic Sequences. John Benjamins, The Netherlands, pp. 249-268.

Wray, A., 2002. Formulaic Language and the Lexicon. Cambridge University Press, UK.

Wray, A., 2000. Formulaic sequences in second language teaching: principle and practice. Appl. Linguistics 21 (4), $463-489$.

Wray, A., Namba, K., 2003. Formulaic language in a Japanese-English bilingual child: a practical approach to data analysis. Jpn. J. Multilingualism Multiculturalism 9 (1), 24-51.

Wray, A., Perkins, M., 2000. The functions of formulaic language: an integrated model. Lang. Commun. 20 (1), 1-28.

Yorio, C., 1989. Idiomaticity as an indicator of second language proficiency. In: Hyltenstam, Kenneth, Obler, Loraine (Eds.), Bilingualism across the Life-span. Cambridge University Press, Cambridge, pp. 55-86.

Yorio, C.A., 1980. Conventionalized language forms and the development of communicative competence. TESOL Q. 14 (4), $433-442$. 